\title{
Preface to the Special Issue
}

DOI: $10.1134 / \mathrm{S} 000143701504013 \mathrm{X}$

Over the past decade, the Arctic Region has been a focus of geopolitical and scientific interest not only of states having Arctic borders but also of countries geographically distant from the Arctic. This is primarily related to the region's colossal resource potential and the deep climate-induced changes underway there; understanding the causes of these changes and forecasting their consequences are strategically important for the countries of the Northern Hemisphere. Attention to the Arctic has triggered increased research activity, and Russia, as the leading Arctic country, is called upon to play a significant role in these studies. The necessity of obtaining new basic knowledge about the Arctic has been fixed in an important state document-The Russian Federation's Arctic Zone Development Strategy to Ensure National Security until 2020 - signed by the Russian president on March 20, 2013.

The current condition and the ongoing climatic and anthropogenic processes in the Arctic Basin are largely predetermined by processes on the shelves of epicontinental Arctic seas. The marginal shelves are regions where the Arctic Basin and the continents interact and where huge amounts of river runoff, $2300-2500 \mathrm{~km}^{3}$ a year, flow into the Arctic Ocean and transform there. Russia owns over $70 \%$ of the Arctic shelf, and the study of the shelf seas is crucial to understand the Arctic as a system with its current vectors and causes of variability.

The key importance of the Kara Sea for the entire Arctic ecosystem is that this sea receives the Arctic's largest river runoff, about $1200 \mathrm{~km}^{3}$ a year $(\sim 45 \%$ of the whole river runoff to the Arctic), draining 5.6 million square kilometers of Siberia (3.7\% of the Earth's dry land!). River runoff freshens the surface layer of the sea, bringing huge amounts of allochthonous nutrients, biological production, waterborne and dissolved terrige- nous materials, and contaminants to the Arctic shelf. Climate change is strongly manifesting itself in the Kara region primarily as the retreat of the summer ice extent to the north compared to its average position over the past 40 years. The Kara shelf and the coastal zone are rich in strategic hydrocarbon resources. Their intensive development will start in the near future, and this is a powerful anthropogenic threat to the basin. The Kara Sea is one of the largest marine radioactive burial grounds in the world, where radioactive waste had been buried from the mid-1950s through 1991. The burials are localized in shallow waters, mostly in semiclosed coastal areas of Novaya Zemlya and the Novozemel'skii trough, their total volume being estimated at $15.5 \mathrm{kCi}$ (574 TBq). The safe preservation periods of several nuclear burials are close to expiration, and this potential source of radioactivity forms the largest accrued environmental risk in the Russian Arctic.

Arctic studies are a priority vector in the research carried out the Institute of Oceanology RAS. The support targeting the study of Arctic ecosystems by the Russian Foundation for Basic Research; the RAS Presidium programs Exploration Basic Research in the Interests of the Russian Arctic Zone Development and Basic Problems of Oceanology: Physics, Geology, Biology, Ecology; and the Russian Scientific Foundation have made it possible to conduct large-scale comprehensive expeditions to the Kara Sea on the research vessels Akademik Mstislav Keldysh and Professor Shtokman in 2007, 2011, 2013, and 2014. The results of these studies are presented in this issue of Oceanology.

M.V. Flint

Translated by B. Alekseev 